\title{
Construction and Testing of Lightweight and Low-Cost Pneumatically Inflated Solar Concentrators
}

\author{
F. M. I. De Los Santos-García, ${ }^{1}$ Y. Nahmad-Molinari, ${ }^{1}$ J. Nieto-Navarro, ${ }^{2}$ \\ C. Alanís-Ruiz, ${ }^{1}$ and Felipe Patiño-Jiménez ${ }^{3}$ \\ ${ }^{1}$ Instituto de Física, Universidad Autónoma de San Luis Potosí, Avenida Manuel Nava 6, 78290 San Luis Potosí, SLP, Mexico \\ ${ }^{2}$ Laboratorio Nacional de la Coordinación para la Innovación y la Aplicación de la Ciencia y la Tecnología, \\ Universidad Autónoma de San Luis Potosí, Sierra Leona 550, 78210 San Luis Potosí, SLP, Mexico \\ ${ }^{3}$ Universidad Tecnológica de Querétaro, Avenida Pie de la Cuesta No. 2501, Unidad Nacional, 76148 Querétaro, QRO, Mexico
}

Correspondence should be addressed to F. M. I. De Los Santos-García; fatima.santos@alumnos.uaslp.edu.mx

Received 28 August 2015; Revised 3 December 2015; Accepted 8 December 2015

Academic Editor: Wilfried G. J. H. M. Van Sark

Copyright (c) 2016 F. M. I. De Los Santos-García et al. This is an open access article distributed under the Creative Commons Attribution License, which permits unrestricted use, distribution, and reproduction in any medium, provided the original work is properly cited.

\begin{abstract}
Design, construction, and evaluation of a cylindrical-trough solar concentrator with $1.3 \mathrm{~m}$ aperture, $2.15 \mathrm{~m}$ length, and $0.54 \mathrm{~m}$ focal length, with heat-pipe or vacuum tube receiver and one axis tracking system, are presented. Design performance was tested under ASHRAE standard 93-1986 (RA 91). The concentrator system is lightweight and inexpensive since it was made of polymeric membranes and was pneumatically inflated to acquire its cylindrical shape achieving good optical quality. Further implementation of a flat and a cylindrical extension of the concentrating mirror as secondary mirrors was incorporated into the concentrator design in order to compensate for seasonal variations of collected radiation. Total initial investment of $\$ 163.30$ or $\$ 58.5 / \mathrm{m}^{2}$ and efficiencies ranging from 33 to $25 \%$ for 25 up to $65^{\circ} \mathrm{C}$ show an excellent cost-performance ratio. Construction, costs, and efficiencies obtained by us and developed by other groups are compared to emphasize the high cost/benefit ratio and efficiencies of this approach.
\end{abstract}

\section{Introduction}

Collection of radiant energy from the Sun is used for electric power generation or conversion to thermal energy for industrial processes. Solar thermal collectors may be used in low-temperature applications as in flat-plate collectors (less than $80^{\circ} \mathrm{C}$ ) or of medium temperature with an optical concentration stage, in which the light first impinges on a reflecting surface and then it is redirected towards a receiving element with selective absorbing properties. Here, energy is transferred to a fluid-usually water-thus rising its temperature, and subsequently, it is stored into a thermally insulated tank.

There are two main types of collectors without concentration, used for household processes (washing, drying, etc.) [1]. The first one is the flat-panel collector and the second one is the evacuated-tube collector; both collect direct and diffuse radiation. On the other hand, main concentration systems are dish collector, parabolic trough, linear Fresnel configuration, and central tower. Concentration systems are used when the temperature to be achieved is beyond $150^{\circ} \mathrm{C}$ as in steam generation systems $[1,2]$.

Due to their geometry, parabolic-trough collectors focus the incident radiation on a focal line, using evacuated tubes as receivers. This type of collector requires tracking the Sun in one or two axes; this increases its complexity and, consequently, the costs of initial investment, as well as operating and maintenance costs, in contrast to the flat-plate collector systems, which have no moving parts [3]. For parabolictrough geometry, a highly reflective aluminum sheet with surface-protective Alanod ${ }^{\circledR}$ multilayer [4] is commonly used in industrial concentrators. On July 11, 2012, it rounded costs of $\$ 58.50$ per square meter. Besides, a supporting structure, in which the aluminum sheet is placed with a Sun-tracking mechanism, is needed. In consequence, this is a system with mobile parts and high price and weight. 
The Institute of Renewable Energy (IER) and the Electrical Research Institute (IIE), both in the state of Morelos in Mexico, have developed projects with parabolic-trough concentrators. Their manufacture and materials costs reached $\$ 1706$ per square meter $[5,6]$. A complete overview of parabolic-trough solar collectors and their applications can be found in the work reported by Fernández-García et al. [2].

In India the reported cost for building a parabolicsolar collector was (around) \$562 per square meter [7]; this collector was made with plywood ISI BWR-IS-303.

Most solar thermal applications for industrial processes have been installed on a relatively small scale and are mostly experimental in nature. Only 85 solar thermal plants for processing heat were reported worldwide in 2008, with an installed capacity of $25 \mathrm{MW}_{\text {th }}\left(35,700 \mathrm{~m}^{2}\right)$ and with an average power of $320 \mathrm{KW}_{\mathrm{th}}$; the capacity of the systems was in the range between $50 \mathrm{KW}_{\text {th }}$ and $1.5 \mathrm{MW}_{\text {th }}$ [9]. This $25 \mathrm{MW}_{\text {th }}$ capacity was a minuscule amount compared to the total industrial demand. Industrial applications typically require high temperatures and great volumes $[1,10]$. Solar thermal systems, when correctly integrated in an industrial process, can provide increased energy efficiency and reduction of carbon-dioxide emissions [11].

Some industrial processes can be driven by mediumtemperature parabolic-trough concentrators (PTCs). For instance, there are different designs of PTCs for production of hot water and low-enthalpy steam. These concentrators are modular, with solar collection areas in the range from 2.5 to $5.0 \mathrm{~m}^{2}[12]$.

In this paper the design of a cylindrical, lightweight, and low-cost concentrator is presented with the objective of assessing its economic viability compared with other systems.

\section{System Description}

The proposed system for water heating consists of a collector, a storage tank, pipelines, and a solar tracking system. The collector designed in this study was installed on the roof of the Institute of Physics of the Autonomous University of San Luis Potosí at coordinates $22^{\circ} 36^{\prime} 12^{\prime \prime}$ north and $100^{\circ} 25^{\prime} 47^{\prime \prime}$ east. The system was north-south oriented, with an east-west Sun tracking. The storage tank was placed next to the cylindrical collector, in a position which does not project shadow on it. CPVC pipes, with a diameter of $1.9 \mathrm{~cm}$, were used and isolated with Armaflex ${ }^{\circledast}$.

2.1. Design Parameters. Frequently, a design is accomplished by first decomposing a system into smaller subsystems and then using a progressive series of four operational stagesFeasibility, Preliminary, Detailed Design, and Revisionthrough which the design is developed to completion, using an iterative scheme [13]. Criteria for materials selection would imply a balance between easiness of acquisition, low cost, light weight, and reasonable mechanical properties [14].

A cylindrical pneumatic concentrator was designed at a very low cost and weight. It was inflated with air, in order to obtain the cylindrical shape. The use of Mylar ${ }^{\circledast}$ allowed us to reduce costs. The cost of Mylar is $\$ 1 / \mathrm{m}^{2}$, which contributes to limit the construction costs of the whole system to a total of $\$ 163.30$. The length of the concentrator is limited by the extension of the receiver. We used commercially available finned heat-pipe tube with a length of $1.6 \mathrm{~m}$ and diameter of $0.068 \mathrm{~m}$. The width of the concentrator was limited by Mylar's commercial dimensions $(1.2 \mathrm{~m})$. It was designed to achieve a focal length of $54 \mathrm{~cm}$, once inflated. This focal length was set in order to have the majority of the deflected raysconsidering spherical aberrations of the cylinder-impinging on the receptor for such aperture.

Later, we tested the same design using anodized aluminum foils (20901L) fabricated by Alanod, as the reflecting surface, instead of Mylar, in order to compare both systems finding equivalent performances. As part of the design of the cylindrical collector, the aluminum foil is not cut or rolled: aluminum foils are installed on the structure without modification; the cylindrical profile is given by the shape of the structure. The total cost of the whole system using Alanod was $\$ 234.1$.

2.2. Receiver (Heat-Pipes Collectors). Receivers use selective AlN coatings as absorber because, with a nonselective absorber, radiation losses would dominate at high temperatures, in such a way that eliminating convection alone would not be very effective [3].

Heat-pipe has a metal absorber mounted within a single envelope vacuum tube. The absorber is thermally connected to a finned heat-pipe, containing acetone that boils and evaporates, transporting by convection the heat absorbed towards a bulb inserted into a manifold, in which the heat is transferred by conduction to the working fluid. Since a glassto-metal seal is used to couple the heat-pipe and the vacuum tube, the cost of these receivers is higher in comparison with simple evacuated tubes.

The heat-pipe is tilted to ensure that once acetone releases its heat into the water, thus condensing, it will flow back to the heated collector to repeat the cycle in which heat always flows in one direction (upwards) driven by convection. This thermal-diode effect is very useful in designing solar thermal collectors, because it automatically shuts the collector off and prevents heat loss by radiation when there is insufficient solar radiation (radiation absorption usually takes place in large areas but they will remain at low temperatures due to their lower vertical position). Also, heat-pipes have lower heat capacity than ordinary liquid-filled absorber tubes, thus minimizing warm-up and cooldown losses [3].

2.3. The Cylindrical Concentrator. The supporting structure for the mirror surface shown in Figure 1 was designed with tubular steel profile with dimensions $2.54 \mathrm{~cm} \times 1.27 \mathrm{~cm}$. The reflecting surface is a cylindrical sector whose radius of curvature is $1.08 \mathrm{~m}$, defining its focus (or center of the circle) at $0.54 \mathrm{~m}$ from the bottom or apex of the cylindrical sector. The cylindrical concentrator has a width of $1.3 \mathrm{~m} \times 2.15 \mathrm{~m}$ length, giving a gross collecting area of $2.79 \mathrm{~m}^{2}$. The sagitta of the circumference is $0.2188 \mathrm{~m}$, and the aperture angle of the circumference used was $74.41^{\circ}$. The units of Figure 1 are in $\mathrm{cm}$. 

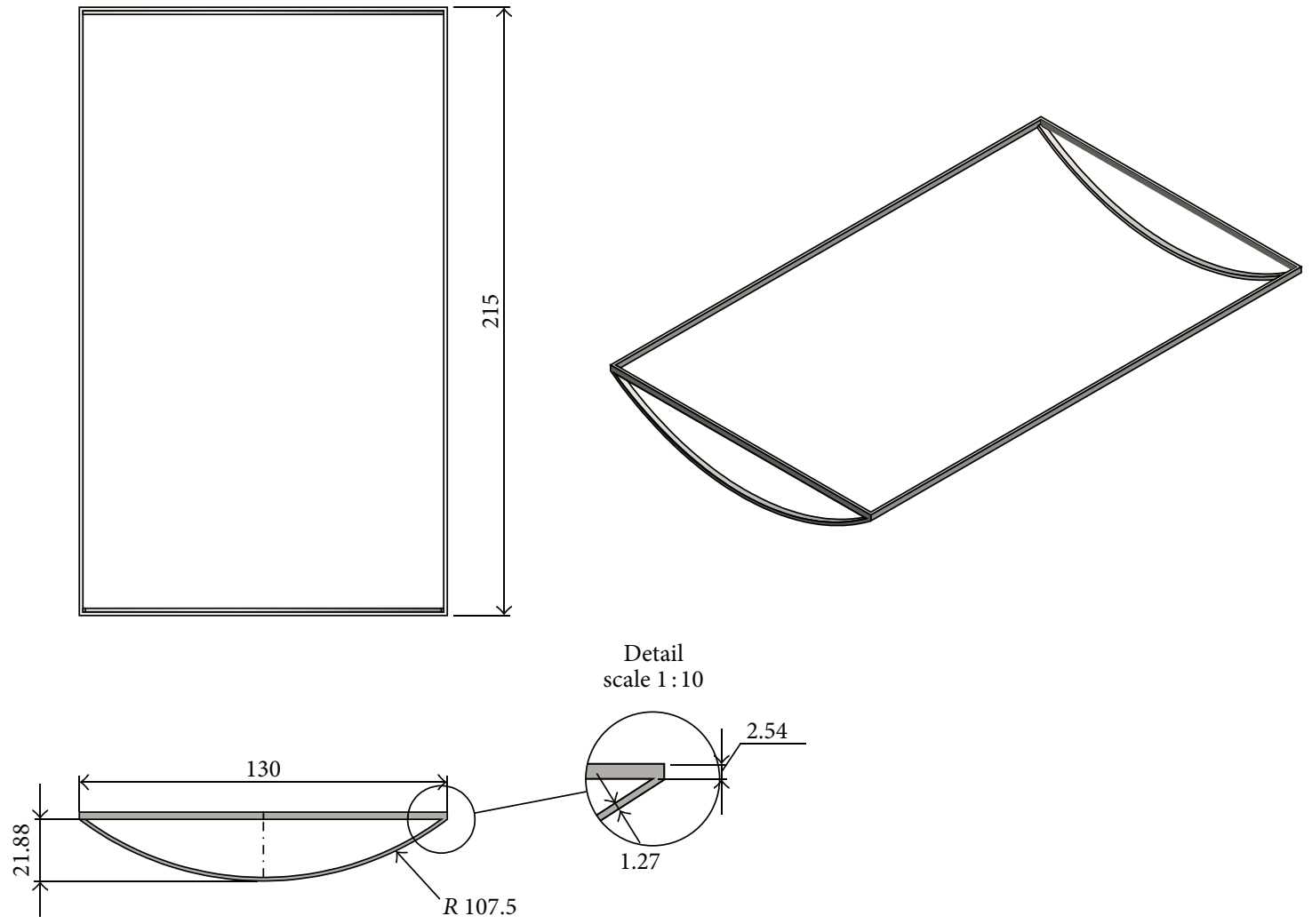

FIgURE 1: Design of the structure of the cylindrical concentrator.

This support structure is covered on the top with a transparent plastic film (polycarbonate) and the reflecting curved surface is of aluminum-metalized plastic film (Mylar). Reflectance of this Mylar, as reported by the manufacturer, is $95 \%$. It has a thickness of $0.05 \mathrm{~mm}$, a density of $139 \mathrm{~kg} / \mathrm{m}^{3}$ or a surface density of $0.02085 \mathrm{~kg} / \mathrm{m}^{2}$, and a price of $\$ 1$ per $\mathrm{m}^{2}$.

The Mylar reflective surface is placed oriented to the Sun's incoming direction and is protected with the transparent polycarbonate film. This polycarbonate has a transmittance of $88 \%$, a thickness of $0.13 \mathrm{~mm}$, a surface density of $1.8 \mathrm{~kg} / \mathrm{m}^{2}$, and a price of $\$ 3.0 / \mathrm{m}^{2}$. The polycarbonate coating is used to protect the Mylar from dust and water (weathering), which causes oxidation of the metalized surface and reflectance losses by detachment of the metallic film, thus increasing the durability of the reflective surface. In addition to the protection provided by this polycarbonate film, its main function is to provide a closed surface, capable of containing air at a pressure slightly greater than atmospheric (around one standard atmosphere). This makes it possible to provide a pneumatic structure with the desired curvature to the entire reflecting surface, by means of Pascal's principle. Air was injected by a domestic air compressor into the chamber through a valve fixed in the concentrator structure, so the air causes the Mylar to tense and adapt, perfectly fitting the cylindrical shape, as shown in Figure 2. This helps to eliminate possible wrinkles of the Mylar caused by its placement on the metal structure. In Figure 2, how the metal frame is covered by the transparent polycarbonate film on its front face and by



FIGURE 2: Cylindrical mirror wrapped with Mylar.

the Mylar film on its rear side can be seen, the metalized side of the latter being in the interior of the concentrator (concave surface).

Following the geometric procedure reported in [1], it is possible to calculate the diameter of the receiver $D$ as a function of the half acceptance angle $\theta_{m}$, the distance from the focus to the vertex, $f$, and the rim angle $\varphi_{r}$. However, in this work, the diameter was chosen by considering the commercially available heat-pipe to reduce construction expenses.

Another important parameter in the cylindrical collector is the collector concentration ratio, $C$, defined as the ratio 
TABLE 1: Collector parameters.

\begin{tabular}{ll}
\hline Collector dimensions & $1.3 \mathrm{~m} \times 2.15 \mathrm{~m}$ \\
\hline$f(\mathrm{~m})$ & 0.54 focal distance \\
\hline$W_{a}(\mathrm{~m})$ & 1.3 \\
\hline$A_{r}\left(\mathrm{~m}^{2}\right)$ & 0.096 \\
\hline$A_{a}\left(\mathrm{~m}^{2}\right)$ & $\begin{array}{l}2.79 \text { aperture area of the cylindrical } \\
\text { collector }\left(\mathrm{m}^{2}\right)\end{array}$ \\
\hline$C(-)$ & 13.54 \\
\hline
\end{tabular}

of the area of aperture $W_{a}$ to the area of the receiver. This parameter for a tubular receiver is given by Kalogirou [1].

The geometric concentration ratio, $C$, is given by

$$
C=\frac{W_{a}}{\pi D_{o}},
$$

where $W_{a}$ is the width of the collector and $D_{o}$ is the outer diameter of the receiver. For a commercial heat-pipe tube an outer diameter of $6.8 \mathrm{~cm}\left(D_{o}=6.8 \mathrm{~cm}\right)$ is used. It is important to point out that the covering surface of the receiver is made of borosilicate glass having transmittance of 0.9 , while the selective surface has an absorptance of $\alpha=0.94$ and an emittance of 0.6 . Table 1 gives a summary of the cylindrical collector parameters.

2.4. Mechanical Tracking System. Two identical rings (Figure 2) made of tubular profile were constructed serving as a supporting structure that turns for tracking the Sun while keeping the receiver at the axis of rotation. In this structure, the cylindrical reflector is placed. To prevent distortion of the rings, three radii were added, as shown in Figure 2, with a support for the receiver in the center. These supports are circles of $7 \mathrm{~cm}$ in diameter, where the heat-pipe tube is placed and matches with the focus of the reflector.

A base of tubular profile was designed with roller bearings to support the structure and allow it to rotate. All this structure obeys the principle of lightness, easiness to move, service, and transport of the entire system (Figure 2).

2.5. Secondary Mirrors. A first flat secondary mirror, which helps to capture further radiation from the Sun, which does not interfere on the receiver due to the lower altitude of the Sun during winter (summer), was designed, thus increasing the net opening area at this season, as shown in Figure 2. Another secondary mirror corresponds to an elongation of the principal mirror towards the south.

The vertical secondary mirror, of Mylar, is placed on the north-side (for the north hemisphere) ring of the concentrator. This mirror helps to capture some of the radiation when the Sun has an inclination due south. The rays first reflect in the mirror to the concentrator and back to the collector (Figure 3).

2.6. Final Prototype. The prototype was installed in a northsouth configuration, tracking the Sun from east to west. The final design of the cylindrical collector for supratropical

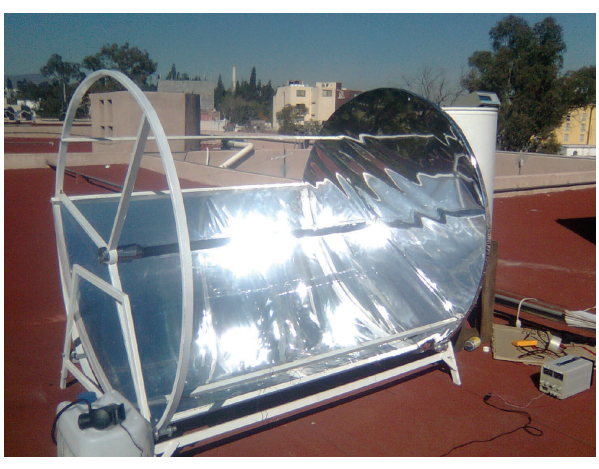

FIGURE 3: Northern flat secondary mirror.

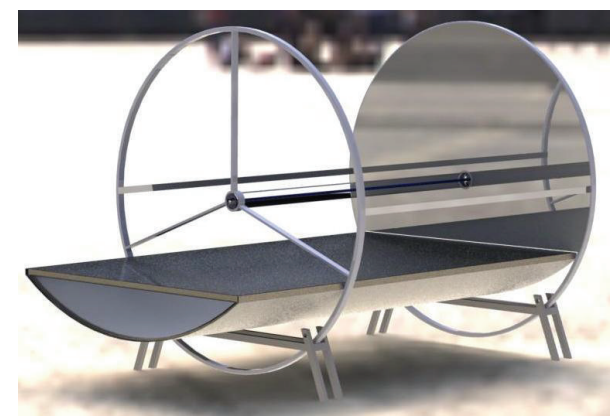

FIGURE 4: Final design of the cylindrical collector showing southern cylindrical and northern flat secondary mirrors for latitudes > $23^{\circ} 26^{\prime} 14^{\prime \prime}$.

latitudes is shown in Figure 4 (for subtropical latitudes the flat secondary mirror should be discarded).

The weight of the entire prototype was $22.3 \mathrm{~kg}$, resulting in a surface density of $8 \mathrm{~kg} / \mathrm{m}$, less than a half of the one reported by $[5,6,15,16]$.

2.7. Hot-Water Storage Tank (HWST). In the design for domestic purposes, the bulb of the heat-pipe is inserted into a thermally insulated reservoir of a 60-liter water tank, covered by $7.5 \mathrm{~cm}$ wide polyurethane foam [17] which is covered by aluminized polyethylene thin film and inserted into an external painted container.

2.8. Electronics of the Tracking System. To detect the Sun's position relative to the cylindrical concentrator, a pair of Light-Dependent Resistors (LDRs) are attached to the concentrator and separated with a small plate in such a way that each LDR will receive an equal amount of light, only if the concentrator is pointing directly towards the Sun: two comparators are used to sense the differential resistance produced by these two LDRs, and they activate a tracking motor to tilt the concentrator on its axis, when the differential resistance becomes too large. An H-drive-transistor switching circuit takes the comparators' output signals and amplifies them to drive a permanent-magnet DC motor one way or the other. This motor move is a Dayton 1LPV8 motor of $12 \mathrm{~V} \mathrm{DC}$ at $2.1 \mathrm{~A}$, with a power of $1 / 30 \mathrm{HP}$. The DC motor is coupled to a reduction gearbox. The final frequency of rotation is 
$6 \mathrm{rpm}$. Two limit switches were added for additional security of the motor and the structure, in emergency situations, and to restore the initial position at the end of the solar day.

\section{Methodology}

3.1. Optical Details. The optical efficiency depends on the optical properties of the materials involved, the geometry of the collector, and the various imperfections arising from the construction of the collector [18]. For optical description of the system, an approximation of a circumference to a parabola was performed, having a maximum error value at the edges of $0.32 \mathrm{~cm}$ and slopes of -0.7235 (circumference) and -0.6428 (parabola), respectively, at the extremes.

Modeling of the shape and placement of reflecting surfaces was made possible with commercial ray-tracing software programs SolTrace and Tonatiuh. SolTrace [19] is optical-modeling software, developed by NREL; Tonatiuh [20] is ray-tracing software, developed by CENER for the optical simulation of solar concentrating systems.

Both programs use the width and length of the receiver, solar radiation incidence angle, the radius of curvature of the mirror, its aperture, and reflectance as input parameters for the calculation of the cylindrical collector.

Results from ray-tracing with SolTrace and Tonatiuh software showed that not all rays reached the focus. The rays that hit on the receiver had an incidence percentage of $94 \%$. Nevertheless we have not characterized the focal spot by absolute measurements; photographic analysis reveals consistency with these simulations.

Thus, considering twice the reflectance of polycarbonate, twice the reflectance of glass, once the reflectance of Mylar, and once the absorptance of the selective surface of the heatpipe fins, one gets an optical efficiency of the system of $\eta_{\text {opt }}=$ 0.57 , but actual thermal measurements give an efficiency value of the system close to 0.32 at low temperatures, as we will see in the next section, which corresponds to 0.88 of light intensity preserved after light interacts with each surface of the system. Nevertheless that 0.88 is a reasonable value; we actually attribute the discrepance between the theoretical and measured values to surface imperfections, deficient Sun tracking, and bad thermal contact during thermal efficiency measurements.

3.2. Thermal Measurements in the System. The instantaneous thermal efficiency can be obtained from an energy balance for the receiver of the collector. The instantaneous efficiency is defined as the rate at which useful energy $q_{u}$ is delivered to the working fluid and divided by the aperture area $A_{a}$ and by the solar flux beam $I_{\mathrm{DN}}$, defined by Rabl [3] and Kalogirou [18]:

$$
\eta_{c}=\frac{q_{u}}{I_{\mathrm{DN}} A_{a}}
$$

where useful heat $q_{u}$ expressed in (2) is related to the mass flow $\dot{m}$, times the specific heat at constant pressure $c_{p}$, and the inlet and outlet temperatures $T_{f \text { in }}$ and $T_{f \text { out }}$, respectively, of the working fluid:

$$
q_{u}=\dot{m} c_{p}\left(T_{f \text { out }}-T_{f \text { in }}\right) .
$$

3.3. Heat Exchanger. In order to characterize the efficiency of the system, a copper jacket heat exchanger was made and the bulb of the heat-pipe was inserted in it. Water was circulated in the jacket at 1.5 liters per minute, and the temperature was measured and registered at the inlet and outlet of the jacket every 10 seconds. Length of the bulb (jacket) is $6 \mathrm{~cm}$ while the diameter of the outer (inner) surface is $1.5 \mathrm{~cm}$, giving $28.27 \mathrm{~cm}^{2}$ of thermal contact surface for heat interchange.

3.4. Thermal Performance. The ASHRAE 93-1986 (RA 91) standard provides test methods for determining the thermal efficiency of concentrating collectors [21]. In our prototype we use J-type thermocouples as shown in Figure 5. T1 sensor is located in the inlet of heat exchanger water jacket, while T2 sensor is located at the exit output. In the water tank we had $\mathrm{T} 3$ at the bottom and T4 at the middle of the tank. We had a $\mathrm{T} 5$ sensor for measuring the ambient temperature.

The system is evaluated considering a recirculation closed-loop. Water from the storage tank is pumped to the water jacket heat exchanger, where it is heated and then flows back into the storage tank.

The experiments have been conducted on various days from 10:00 am to 4:00 pm local time in Central Mexico with a mean solar radiation in the range of $600-900 \mathrm{~W} / \mathrm{m}^{2}$ and a mean room temperature in the range of $20-25^{\circ} \mathrm{C}$.

For data acquisition of temperature the measuring equipment was a Digi-Sense Model 92000-00 from Cole Parmer. It has an ability to read up to 12 thermocouples, with a resolution of $0.1^{\circ} \mathrm{C}$, and can be programmed to measure at different time intervals.

\section{Manufacturing Costs}

Production costs of this prototype are broken down to show how cheap it is, compared with commercially available designs.

As can be seen in Table 2 the total price of this prototype is $\$ 163.30$ for an area of $2.79 \mathrm{~m}^{2}$. Thus, this prototype has a cost of $\$ 58.50 / \mathrm{m}^{2}$. Our lightweight prototype reaches a very low cost, compared to the $\$ 1,706$ per $\mathrm{m}^{2}$ of IER [5] and $\$ 1400$ per $\mathrm{m}^{2}$ reported by the IIE institutes [6]. Reported mediumtemperature solar collectors costs range between $195 \mathrm{US} / \mathrm{m}^{2}$ and $390 \mathrm{US} / \mathrm{m}^{2}[15,22]$.

\section{Results and Discussion}

The prototype was tested according to the ASHRAE 961986 standard [21]. During tests the systems were oriented to determine the thermal efficiency for the heat-pipe receiver under direct sunlight illumination, without the concentrator and for the same heat-pipe receiver with concentrator.

The heat-pipe was inserted into the water jacket heat exchanger. The storage tank was filled with 11.0 liters of water 
TABLE 2: Cost of the solar cylindrical collector.

\begin{tabular}{|c|c|c|c|}
\hline Quantity & Description & $\begin{array}{c}\text { Price/unit } \\
\$\end{array}$ & $\begin{array}{c}\text { Cost } \\
\$\end{array}$ \\
\hline 2 tranches & Tubular profile $1^{\prime \prime} \times 1 / 2^{\prime \prime}$ & 11.42 & 22.85 \\
\hline 2 tranches & Tubular profile $1^{\prime \prime} \times 3 / 4^{\prime \prime}$ & 11.24 & 22.48 \\
\hline 4 & Hubs of bicycle & 1.27 & 5.10 \\
\hline 1 & Plastic tank & 2.25 & 2.25 \\
\hline 1 & Tank 60 liters & 2.25 & 2.25 \\
\hline $4 \mathrm{~m}$ & Polycarbonate & 0.9 & 3.6 \\
\hline 1 & Construction of Sun-tracking circuit & 7.49 & 7.49 \\
\hline 1 & Heat-pipe tube & 7.49 & 7.49 \\
\hline 1 & Heat exchanger & 7.49 & 7.49 \\
\hline $2 \mathrm{~m}$ & Insulating tubing & 0.97 & 1.95 \\
\hline $2 \mathrm{~m}$ & CPVC pipe $3 / 4^{\prime \prime}$ & 1.87 & 1.87 \\
\hline 4 & Unions for pipeline & 1.50 & 6.00 \\
\hline 1 & Engine C.D. & 22.48 & 22.48 \\
\hline \multirow[t]{2}{*}{$6 \mathrm{~m}$} & Mylar & 0.75 & 0.75 \\
\hline & Manufacturing costs & 50.00 & 50.00 \\
\hline \multirow[t]{2}{*}{ Total } & & & 163.30 \\
\hline & Total cost per $\mathrm{m}^{2}$ & & 58.50 \\
\hline
\end{tabular}

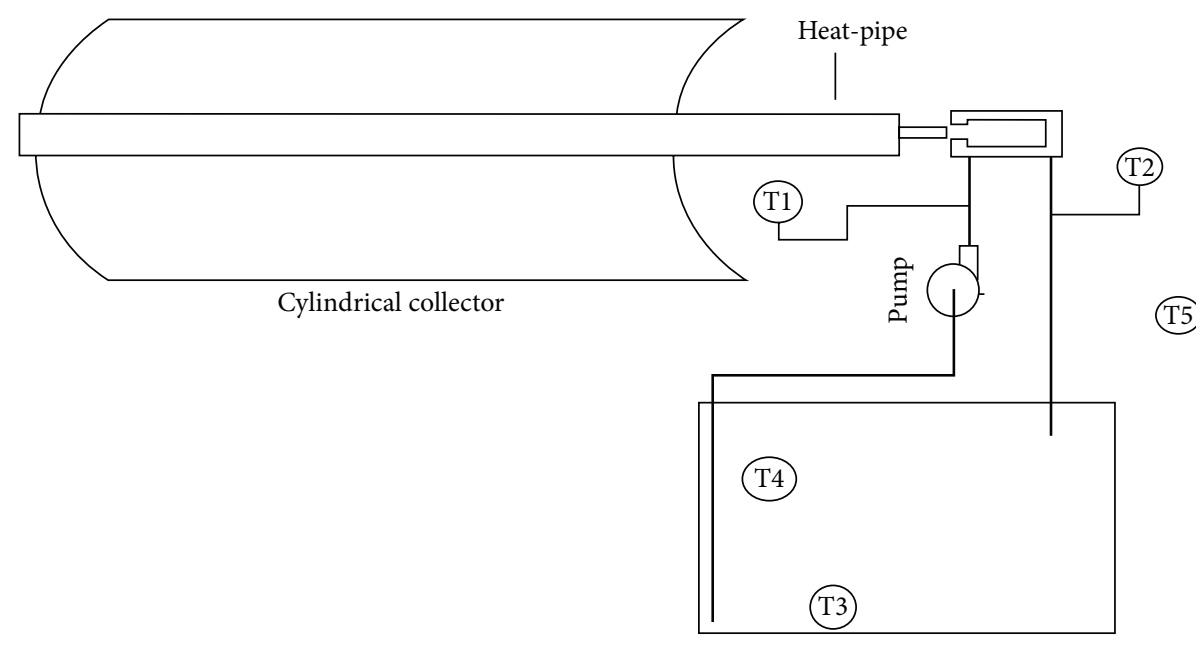

FIGURE 5: Diagram of the experimental system.

that were circulated through the heat exchanger at $1.5 \mathrm{~L} / \mathrm{min}$. The temperature was measured at the inflow and at outflow of the heat exchanger.

Thermal efficiency was calculated by considering the temperature rise across the heat exchanger and using the thermal efficiency equations ((2) and (3)). In Figure 6 results are plotted against $\left(T_{f i}-T_{a}\right) / I$, where $T_{a}$ is ambient temperature, $T_{f i}$ is the inlet temperature on heat exchanger water jacket, and $I$ is the irradiance. In this study, the maximum temperature was restricted to $80^{\circ} \mathrm{C}$ due to limitations in the fluid circulation system.

The efficiency curve for both heat-pipe with concentration and heat-pipe without concentration, shown in Figure 6, shows the thermal instantaneous efficiency and its linear fit.

The test conducted using the heat-pipe tube under concentration conditions resulted in an efficiency of 0.30 , decreasing just slightly for a wide range of temperatures. The test conducted using the heat-pipe tube without concentration results in an efficiency of 0.9 for low temperatures, but efficiency drops sharply when temperature increases.

We then compared our results with those of Vidriales Escobar (2007), who used a parabolic concentrator, obtaining a curve presented here, with the parameters in Table 3 [8].

The test reported by Vidriales Escobar was conducted for 10 liters of water with a flux of $0.35 \mathrm{~L} / \mathrm{min}$ and $872.6 \mathrm{~W} / \mathrm{m}^{2}$ of 
TABLE 3: Parameters of collector of Vidriales Escobar.

\begin{tabular}{ll}
\hline Collector dimensions & $1.049 \mathrm{~m} \times 2.44 \mathrm{~m}$ \\
\hline$f(\mathrm{~m})$ & 0.25 focal distance \\
\hline$W_{a}(\mathrm{~m})$ & 1.049 \\
\hline$D_{o}(\mathrm{~m})$ & 0.0364 \\
\hline$A_{a}\left(\mathrm{~m}^{2}\right)$ & $\begin{array}{l}2.56 \text { aperture area of the cylindrical } \\
\text { collector }\left(\mathrm{m}^{2}\right)\end{array}$ \\
\hline$C(-)$ & 11.17 \\
\hline
\end{tabular}

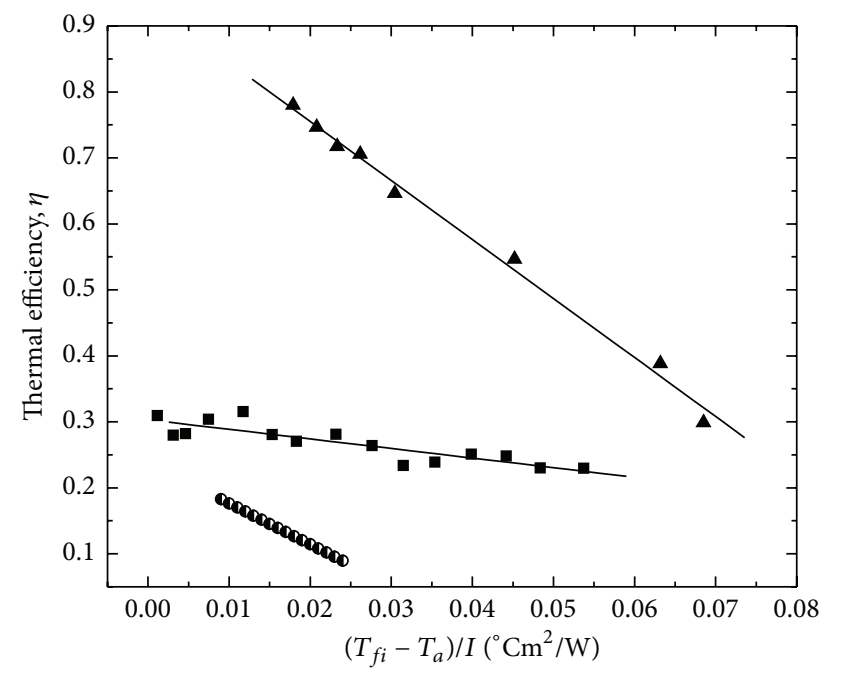

- Heat-pipe with concentration

- Heat-pipe without concentration

- Vidriales Escobar (2007)

FIgure 6: Thermal efficiency data for heat-pipe with concentration and heat-pipe without concentration and Vidriales Escobar [8].

irradiance at ambient temperature of $32.85^{\circ} \mathrm{C}$, on March 31, 2006. The test starts with an inlet temperature of $45.35^{\circ} \mathrm{C}$. We can observe that our cylindrical collector has almost twice the efficiency reported by Vidriales Escobar.

Different concentration systems that include inflatable structures have been developed by some groups intended for deployable antenna or concentrated photovoltaic systems in Earth or in space: Cassapakis and Thomas [23], Carrasquillo De Armas [24], O’Neill [25], and a company called Cool Earth Solar [26]. One approach in forming concave mirrors is to stretch the metalized membrane by uniform pressure application as in the case of mirrors reported by Murphy and Tuan [27] and Jenkins et al. [28] and others like Cassapakis and Thomas [23], O'Neill and Piszczor [29], and CoolEarthSolar.com [26] which differs from our approach in the fact that stretching is negligible in our case. Inner pressure in our case is just above the atmospheric pressure in order to give uniform support to the Mylar film, but the curvature is given by the metallic frame which is commensurable with the length of the film, not by stretching as in the above cited studies. Inflatable concentrators deployed in space could be used without continuous inflation if a rigidization process is used on the reflecting membrane; however in Earth based applications this would lead to a large increase in the density of the reflector to prevent deformations under their own weight, Redell et al. [30].

Some considerations about durability and resistance to outdoor conditions are that Mylar has a longevity larger than a year without presenting aluminum detachment if it is correctly oriented with the aluminum layer at the interior of the inflated mirror as we and Deyle [31] have observed. Polycarbonate film is UV resistant conferring to the mirror longevity at least equal to the Mylar film if correctly cleaned by using distilled water only. Puncturing by strange objects or detachment from the supporting frame is the most frequently observed event since tests were running on the system. The detachment from the frame and punctures can be easily corrected using transparent tape which resist at least 6 months at outdoor conditions, Deyle [31].

\section{Conclusions}

A novel cylindrical-trough pneumatically inflated concentrator is presented. Good, stable performance in lowtemperature applications is achieved as compared against other similar concentrators reported in the literature. Lightweight and good-optical-quality concentrators result from combining thin frame structures with flexible polymeric membranes, giving a competitive $8 \mathrm{~kg} / \mathrm{m}^{2}$ surface density in comparison with typical few tenths of $\mathrm{kg} / \mathrm{m}^{2}$ reported for similar systems.

Implementation of secondary mirrors in order to further enhance the collection of solar energy and compensate for seasonal variations in Sun-energy capture due to declination changes is reported.

In addition, we have shown with this design that a far lower cost can be achieved for a pneumatically inflated lightweight concentrator. We have compared our costs of production with others reported in the literature, showing that our approach lowers 29 times the initial investment, with the construction costs of the system kept below a total of $\$ 163.30$.

This collector shows good potential as a source of process heat for developing countries, where it could be an appropriated technology at competitive costs achieving good thermal efficiency.

\section{Conflict of Interests}

The authors declare no conflict of interests.

\section{Acknowledgments}

The authors wish to thank Enrique Martínez Hernández for his technical assistance in the construction of the concentrator and Gregor Zieke for reading the paper. This work was supported by Inter-American Development Bank ATN/KK11514-RG, ATN/13990-RG, Universidad Autónoma de San Luis Potosí C14-FAI-08-67.67, CONACYT Ciencia Básica 221961, and CONACYT for Scholarship 327853. 


\section{References}

[1] S. A. Kalogirou, "Solar thermal collectors and applications," Progress in Energy and Combustion Science, vol. 30, no. 3, pp. 231-295, 2004.

[2] A. Fernández-García, E. Zarza, L. Valenzuela, and M. Pérez, "Parabolic-trough solar collectors and their applications," Renewable and Sustainable Energy Reviews, vol. 14, no. 7, pp. 1695-1721, 2010.

[3] A. Rabl, Active Solar Collectors and Their Applications, Oxford University Press, New York, NY, USA, 1984.

[4] ALANOD Aluminium-Veredlung GmbH \& Co. KG, 2014, http://alanod.com/opencms/opencms/en/index.html.

[5] E. Venegas Reyes, Diseño, Construcción y Evaluación de un Arreglo de Concentradores de Canal Parabólico para Calor de Proceso, Tesis IER-UNAM, 2013.

[6] C. Ramos Berumen, Taller de Sistemas Termosolares a concentración, Impartido el 29 de Septiembre 2011 en San Luis Potosí, por Instituto de Investigaciones Eléctricas, 2011.

[7] A. V. Arasu and T. Sornakumar, "Design, manufacture and testing of fiberglass reinforced parabola trough for parabolic trough solar collectors," Solar Energy, vol. 81, no. 10, pp. 12731279, 2007.

[8] L. G. Vidriales Escobar, Colector de canal parabólico para la generación directa de vapor para calor de proceso [Tesis CIE], Universidad Nacional Autónoma de México (UNAM), Mexico City, Mexico, 2007.

[9] C. Vannoni, R. Battisti, and S. Drigo, Eds., Potential for Solar Heat in Industrial Processes, Solar Heating and Cooling Executive Committee of the International Energy Agency, Rome, Italy, 2008.

[10] H. Schnitzer, C. Brunner, and G. Gwehenberger, "Minimizing greenhouse gas emissions through the application of solar thermal energy in industrial processes," Journal of Cleaner Production, vol. 15, no. 13-14, pp. 1271-1286, 2007.

[11] M. J. Atkins, M. R. W. Walmsley, and A. S. Morrison, "Integration of solar thermal for improved energy efficiency in lowtemperature-pinch industrial processes," Energy, vol. 35, no. 5, pp. 1867-1873, 2010.

[12] E. Venegas-Reyes, O. A. Jaramillo, R. Castrejón-García, J. O. Aguilar, and F. Sosa-Montemayor, "Design, construction, and testing of a parabolic trough solar concentrator for hot water and low enthalpy steam generation," Journal of Renewable and Sustainable Energy, vol. 4, no. 5, Article ID 053103, 2012.

[13] H. M. Güven, F. Mistree, and R. B. Bannerot, "A conceptual basis for the design of parabolic troughs for different design environments," Journal of Solar Energy Engineering, vol. 108, no. 1, pp. 60-66, 1986.

[14] M. J. Clifford and D. Eastwood, "Design of a novel passive solar tracker," Solar Energy, vol. 77, no. 3, pp. 269-280, 2004.

[15] U. Herrmann and P. Nava, "Performance of the SKAL-ET collector of the andasol power plants," in Proceedings of the 14th International SolarPACES Symposium on Solar Thermal Concentrating Technologies, Las Vegas, Nev, USA, 2008.

[16] M. Geyer and E. Lupfert, "EUROTROUGH—parabolic trough collector developed for cost efficient solar power generation," in Proceedings of the 11th SolarPACES International Symposium on Concentrated Solar Power and Chemical Energy Technologies, Zurich, Switzerland, September 2002.

[17] Centro de Tecnología Educativa (CET), Curso de Energía Solar Tomo III, Centro de Tecnología Educativa (CET), Barcelona, Spain, 1994.
[18] S. A. Kalogirou, "Parabolic trough collector system for low temperature steam generation design and performance characteristics," Applied Energy, vol. 55, no. 1, pp. 1-19, 1996.

[19] NREL National Renewable Energy Laboratory, SolTrace Optical Modeling Software, 2012, http://www.nrel.gov/csp/soltrace/ download.html.

[20] Tonatiuh-A Monte Carlo ray tracer for the optical simulation of solar concentrating systems, 2012, https://code.google.com/ $\mathrm{p} /$ tonatiuh/.

[21] ANSI/ASHRAE 93-1986 (RA 91), Methods of Testing to Determine the Thermal Performance of Solar Collectors, American Society of Heating, Refrigerating and Air-Conditioning Engineers, 1993.

[22] W. Weis, AEE INTEC, M. Rommel, and Fraunhofer, Solar Heat for Industrial Processes, Medium Temperature Collectors, State of the Art within Task 33/IV, Subtask C, Solar Heating and cooling Executive Committee of the International Energy Agency (IEA), 2005.

[23] C. Cassapakis and M. Thomas, Inflatable Structures Technology Development Overview, 2015, http://www.lgarde.com/assets/ content/files/publications/overview.pdf.

[24] O. Y. Carrasquillo De Armas, Design of inflatable solar concentrator [M.S. thesis], Department of Mechanical Engineering, Massachusetts Institute of Technology, Cambridge, Mass, USA, 2013, http://hdl.handle.net/1721.1/84399.

[25] M. J. O’Neill, "Inflatable fresnel lens solar concentrator for space power," US Patent No. 6,111,190 (Filed in 1998).

[26] Cool Earth Solar: Solar Power 2006 Presentation, 2015, http:// www.coolearthsolar.com/.

[27] L. M. Murphy and C. Tuan, The Formation of Optical Membrane Reflector Surfaces Using Uniform Pressure Loading, 1987.

[28] C. H. Jenkins, V. D. Kalanovic, K. Padmanabhan, and S. M. Faisal, "Intelligent shape control for precision membrane antennae and reflectors in space," Smart Materials and Structures, vol. 8, no. 6, pp. 857-867, 1999.

[29] M. J. O’Neill and M. F. Piszczor, "Inflatable lenses for space photovoltaic concentrator arrays," in Proceedings of the Conference Record of the 26th IEEE Photovoltaic Specialists, pp. 853-856, Anaheim, Calif, USA, October 1997.

[30] F. H. Redell, J. Kleber, D. Lichodziejewski, and G. Greschik, "Inflatable-rigidizable solar concentrators for space power applications," in Proceedings of the 46th AIAA/ASME/ASCE/ AHS/ASC Structures, Structural Dynamics, and Materials Conference, pp. 1-10, Austin, Tex, USA, April 2005.

[31] T. Deyle, Inflatable Membrane Solar Concentration Systems for Space-Based Applications, 2015, http://www.travisdeyle.com/ files/publications/PV_TermPaper.pdf. 

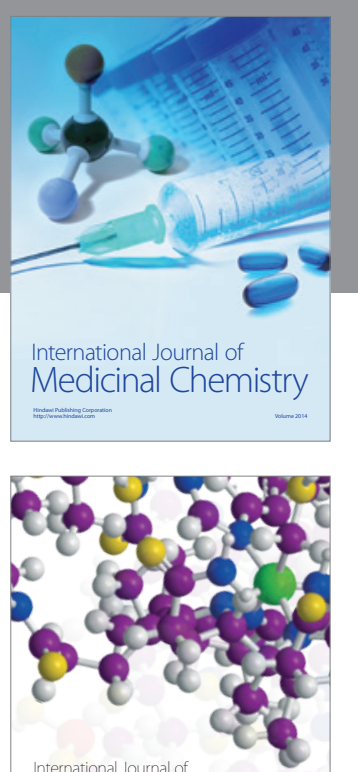

Carbohydrate Chemistry

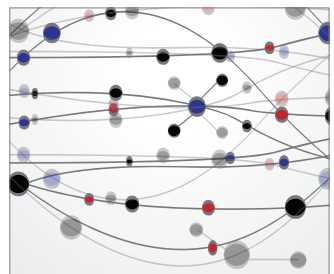

The Scientific World Journal
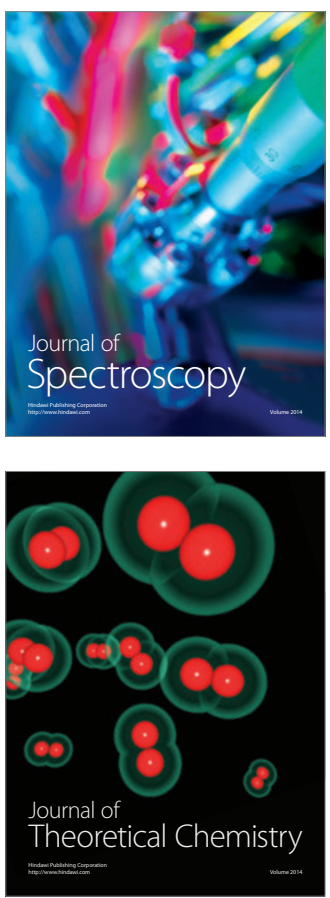


Submit your manuscripts at

http://www.hindawi.com

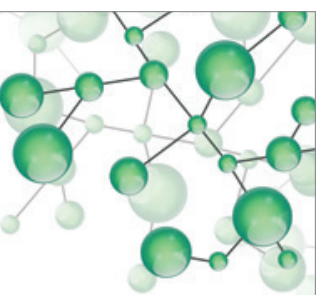

International Journal of

Inorganic Chemistry

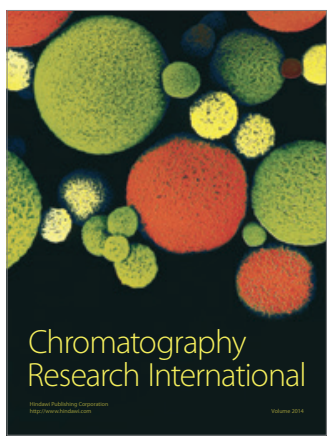



Applied Chemistry
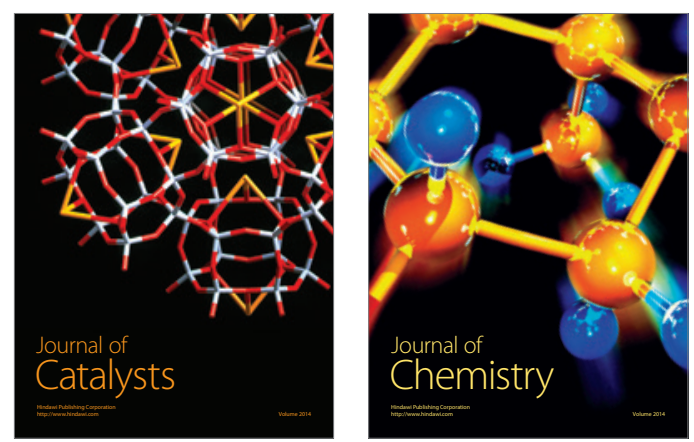
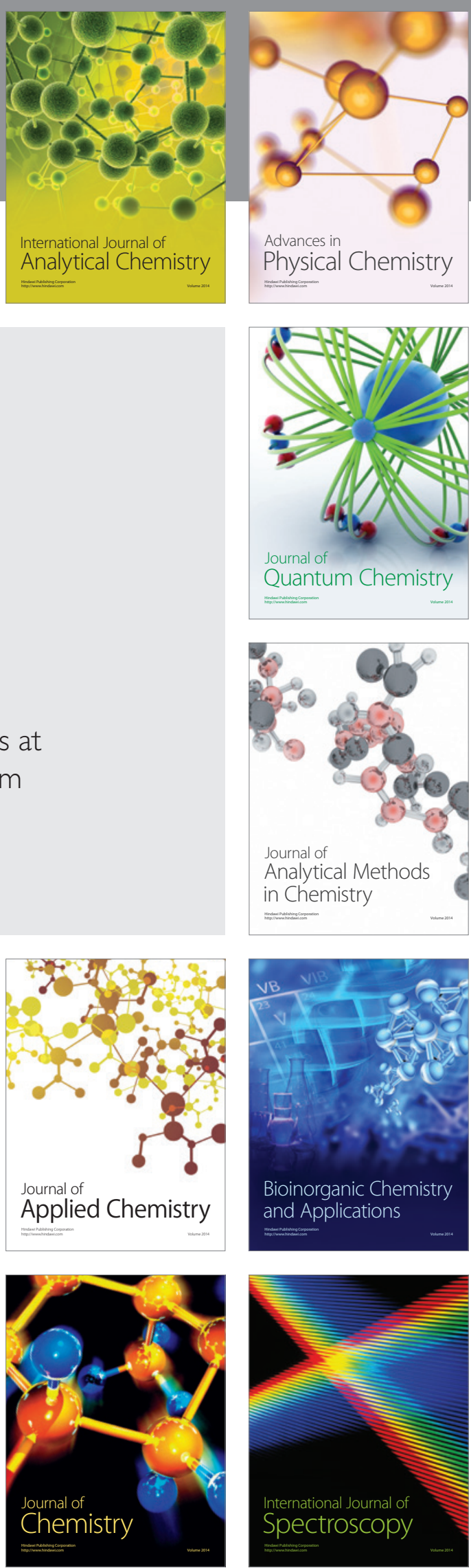